\title{
Containing cefoxitin costs through a program to curtail use in surgical prophylaxis
}

\author{
Geoffrey Taylor, MD, Edith Blondel-Hill, MD, PAmela KibSey, MD, ERWIN Friesen, PharmD, \\ RONALD TISDELL, BSC, WENDY VAUDRY, MD
}

\begin{abstract}
G TAYLoR, E Blondel-Hill, P Kibsey, E Friesen, R Tisdell, W VAudRY. Containing cefoxitin costs through a program to curtail use in surgical prophylaxis. Can $J$ Infect Dis 1993;4(5):275-278.

OBJEctrve: To reduce drug costs attributable to anti-anaerobic cephalosporins - specifically to reduce cefoxitin use in surgical prophylaxis. Design: Before and after intervention cefoxitin use comparison. Setring: Tertiary care hospital. PARTICIPANTS: Hospitalized patients. InTERventions: Chart review of patients identified through pharmacy records as cefoxitin recipients was carried out to determine which physicians were the principal users of cefoxitin and the purpose for such use. These data were used to direct cost containment strategies. Marn Outcome Measures: Hospital quarterly pharmacy acquisition costs and grams of cefoxitin used. Results: The departments of surgery (49\%) and obstetrics/gynecology $(37 \%)$ were the principal users of cefoxitin, and surgical prophylaxis was found to be the principal indication for use (63\%). These departments were invited by the Antibiotic Utilization Subcommittee of the hospital's Pharmacy and Therapeutics Committee to draft surgical prophylaxis guidelines in keeping with published recommendations. Such guidelines were written and distributed to medical staff and substituted cefazolin for most forms of prophylaxis, gentamicin/metronidazole for colorectal prophylaxis and cefoxitin only for appendectomies. Over the following 21 months, hospital-wide cefoxitin use fell from $6093 \mathrm{~g}$, \$70,076 per quarter, to $1316 \mathrm{~g}$, \$11,515 per quarter (partially offset by a $2595 \mathrm{~g}, \$ 9,131$ per quarter increase in cefazolin use). ConcLusion: As a first step in reducing hospital costs of anti-anaerobic cephalosporins, rationalization of cefoxitin use may be preferable to formulary interchange with alternatives such as ceftizoxime or cefotetan.
\end{abstract}

Key Words: Antibiotic cost containment, Cefoxitin, Surgical prophylaxis

\section{Comment limiter les coûts de la céfoxitine au moyen d'un programme de réduction de son utilisation en prophylaxie chirurgicale}

Oв.JеCTF : Diminuer les coûte de l'utilisation des céphalosporines anti-anaérobies et tout particulièrement en réduisant l'utilisation de la céfoxitine en prophylaxie chirurgicale. Méthodologre : Comparaison de l'utilisation de la céfoxitine avant et après intervention du programme. CADre : Hôpital de soins tertiaires. Participants : Patients hospitalisés. INTERVENTIONS : Une revue détaillée des patients identifiés grâce aux registres de la pharmacie comme ayant reçu de la céfoxitine, a été effectuée afin de déterminer les médecins qui étaient les principaux utilisateurs de céfoxitine ainsi que la but de cette utilisation. Les données obtenues ont été utilisêes pour préparer des stratégies de réduction des coûts. Principaux indicateurs des résultats : Coûts d'acquisition trimestriels de la pharmacie de l'hôpital et nombre de grammes de céfoxitine utilisés. Résultats : Les services de chirurgie (49\%) et d'obstétrique/gynécologie (37\%) ont été les principaux utilisateurs de céfoxitine, et la prophylaxie chirurgicale a été notée comme le principal objet de son indication: $66 \%$. Ces services ont été invités par le sous-comité d'utilisation des antibiotiques du comité de pharmacologie et de thérapeutique de l'hôpital à établir des directives de prophylaxie chirurgicale en accord avec les recommandations publiées. Ces directives ont été rédigées et distribuées au personnel médical : elles consistent à

Departments of Medicine, Pediatrics, Laboratory Medicine, and Pharmacy, University of Alberta Hospitals, Edmonton, Alberta Correspondence and reprints: Dr GD Taylor, 2E4.11 Walter Mackenzie Centre, University of Alberta, Edmonton, 
remplacer la céfoxitine par la céfazoline pour la plupart des formes de prophylaxie; par la gentamicine/métronidazole pour la prophylaxie colorectale, en réservant la céfoxitlne uniquement aux appendicectomies. Pendant les 21 mois suivants, l'utilisation de la céfoxitine dans tout l'hôpital est passée de 6093 g, soit 70076 \$ par trimestre, à 1316 g, c'est-à-dire 11515 \$ par trimestre (différence partiellement compensée par une augmentation de 2595 g, soit 9131 \$ par trimestre de frais d'utilisation de la céfazoline). Conclusion : En première étape du programme de réduction des coûts hospitaliers des céphalosporines anti-anaérobies, la rationalisation de l'utilisation de la céfoxitine est préférable aux substitutions par d'autres produits du formulaire comme le ceftizoxime ou le céfotétan.

$\mathrm{M}$ ODERN ANTIMICROBIAL DRUG THERAPY OF HOSPITALIZED patients, while highly efficacious, can also be expensive. In North American hospitals, antimicrobials consume 20 to $40 \%$ of all drug acquisition costs $(1,2)$. Cephalosporin antimicrobials are particularly expensive, accounting for 36 to $59 \%$ of antimicrobial purchase costs $(3,4)$. Cefoxitin, a second generation cephalosporin with a broad spectrum of activity against aerobic Gram-negative and Gram-positive bacteria as well as anti-anaerobic bacterial activity (5), has been a very popular drug for in-hospital use since its introduction in the 1970s. In 1984 cefoxitin led all other drugs in the United States in terms of hospital sales (4). There is, however, substantial published evidence of widespread use of cefoxitin when narrower spectrum (and less expensive) agents would suffice $(4,6)$.

Recently, two new cephalosporin drugs with antianerobic activity have been marketed in Canada as less expensive alternatives to cefoxitin: cefotetan and ceftizoxime $(7,8)$. In an effort to reduce costs of antimicrobial therapy, it has been suggested that hospitals might delete cefoxitin from their formularies and substitute either cefotetan or ceftizoxime (9-11); however, merely to substitute one of these newer agents for cefoxitin could be regarded as substituting one inappropriately used agent for another. Rather than substitute cefotetan or ceftizoxime for cefoxitin, we chose to determine to what extent cefoxitin misuse was occurring in our hospital and tried to improve its use.

\section{METHODS}

The University of Alberta Hospital is an 1100 bed tertiary care hospital serving northern Alberta. The annual drug acquisition budget has been in the order of $\$ 5$ million with antimicrobials accounting for about $25 \%$ of this amount. Cefoxitin has traditionally been among the top five drugs in terms of acquisition costs, with steadily increasing expenditures. In the fiscal year 1984-85, \$159,355 was spent acquiring 19,920 g of cefoxitin; by $1989-90$ this had increased to $\$ 238,882$ to acquire $19,770 \mathrm{~g}$ (reflecting a price increase from $\$ 8.00$ to $\$ 11.50 / \mathrm{g})$.

In the spring of 1990, at a time of serious budgetary crisis for the authors' hospital, the Antibiotic Utilization Subcommittee of the hospital's Pharmacy and Therapeutics Committee decided to target cefoxitin as part of its cost containment strategy. A previously completed chart review study of 152 consecutive courses of cefoxitin use in the same institution had shown that the majority of use was in the departments of surgery $(49 \%$ of cases) and obstetrics/gynecology (37\%) (unpublished data). This study also showed that $63 \%$ of all patients receiving cefoxitin did so for the purpose of surgical prophylaxis and only $37 \%$ of treatment courses were given to manage established infection. Efforts were, therefore, principally directed at these two groups and, in particular, at their antibiotic prophylaxis regimens.

The subcommittee invited the departments of obstetrics/gynecology and surgery to participate in a review of cefoxitin use. Neither department had developed guidelines for antibacterial surgical prophylaxis, leaving the decision as to which patients would be given prophylaxis, which agents would be used and duration of prophylaxis to individual surgeons. It was pointed out that while it is an effective prophylactic agent, cefoxitin had not been shown to be superior to other agents for any surgical procedure and was not recommended as a first-line prophylactic agent for any indication except appendectomy (12-14). Following a review of the literature, the departments agreed to draw up routine surgical prophylaxis guidelines. In keeping with published guidelines, cefazolin was specified as the agent of choice for head and neck, gastroduodenal, high risk biliary tract, hysterectomy and high risk caesarean section surgical procedures. Metronidazole plus gentamicin were chosen for colonic surgery (15) and cefoxitin for appendectomy (14). Guidelines were distributed to attending physicians and residents in the departments of surgery and obstetrics/gynecology, and additional cefoxitin information was included in a Pharmacy and Therapeutics Committee newsletter to all medical staff. To forestall any pharmaceutical industry response to declining cefoxitin use it was made clear that failure of this approach would very likely lead to complete elimination of cefoxitin from the formulary.

To observe the outcome of the interventions, hospitalwide pharmacy cefoxitin acquisition data (total grams and costs) were analyzed over 21 months from the initiation of the process (April 1990 to December 1991).

\section{RESULTS}

For the fiscal year 1989-90, ie, just before implementation of the initiatives, the hospital spent $\$ 238,882$ $(19,770 \mathrm{~g}$ ) or $\$ 59,720$ per quarter (4942 g) on cefoxitin. In the first quarter of 1990-91, during the implementation of initiatives, this rose to $\$ 70,076$ (6093 g). Subsequently, there has been a fall in costs related to cefoxitin acquisition (Figure 1) and number of grams 
used (Figure 2). In the third quarter of 1991 (October to December), the price of cefoxitin was reduced from $\$ 11.50$ to $\$ 8.75 / \mathrm{g}$ adding to the cost savings. Altogether in fiscal year 1990-91 cefoxitin expenditures were $\$ 169,683$, a drop of $\$ 69,199$ compared with the previous fiscal year. If the level of use for the first three quarters (April to December) of 1991-92 can be maintained, the annual costs would be reduced to $\$ 56,743$, a saving of $\$ 182,139$ over 1989-90.

During this period, cefazolin use increased by $31 \%-$ from $8339 \mathrm{~g}$ in the first quarter of 1990 (April to June) to $10,934 \mathrm{~g}$ (October to December 1991) - but this resulted in only a $\$ 6,905$ increase in per quarter costs, reflecting its much lower acquisition price $(\$ 2.45 / \mathrm{g})$. These changes occurred in the context of no change to the hospital's in-patient admissions rate (mean during the study period, 2485 per month, range 2019 to 2794) or numbers of surgical procedures performed (mean 1134 per month range 892 to 1318 ).

\section{DISCUSSION}

This study has shown that considerable reductions in expenditures on anti-anaerobic cephalosporins can be achieved through a process of curtailing cefoxitin use. We feel that the concept of cefoxitin rationalization through curtailment is preferable, initially, to formulary interchange with cefotetan or ceftizoxime. Exchanging one drug for another depends on the new agent having at least an equivalent safety and therapeutic profile to the older agent. In our opinion, cefotetan and ceftizoxime, while promising, have not been shown to be equal in clinical efficacy or safety to cefoxitin for treatment or prophylaxis $(7,16-18)$. Furthermore, the concept of reducing costs through the interchange process assumes the older agent is already being used in the most cost effective manner (clearly not the case with cefoxitin in many hospitals). Finally, drug interchange depends on the newer agent being used at the same rate as the older one (eg, cefoxitin). If the newer agent is more frequently prescribed, for example as physicians attempt to acquire familiarity with the drug, cost savings will be reduced or even eliminated.

Some of the reduction achieved in cefoxitin use has been offset by increased use of other agents, especially cefazolin, in surgical prophylaxis. Since cefazolin is a much cheaper agent than cefoxitin $(\$ 2.45 / \mathrm{g}$ for cefazolin versus $\$ 8.75 / \mathrm{g}$ for cefoxitin at our hospital), major overall cost savings will still be achieved and are at least comparable to those that could have been achieved through interchange. It remains to be seen whether cost reductions in cefoxitin use can be maintained over the long term. However, by continuously monitoring cefoxitin use and by forestalling pharmaceutical industry marketing responses to decreased sales by the threat of deleting it from the formulary, we hope to be able to respond if increased use occurs. There might be

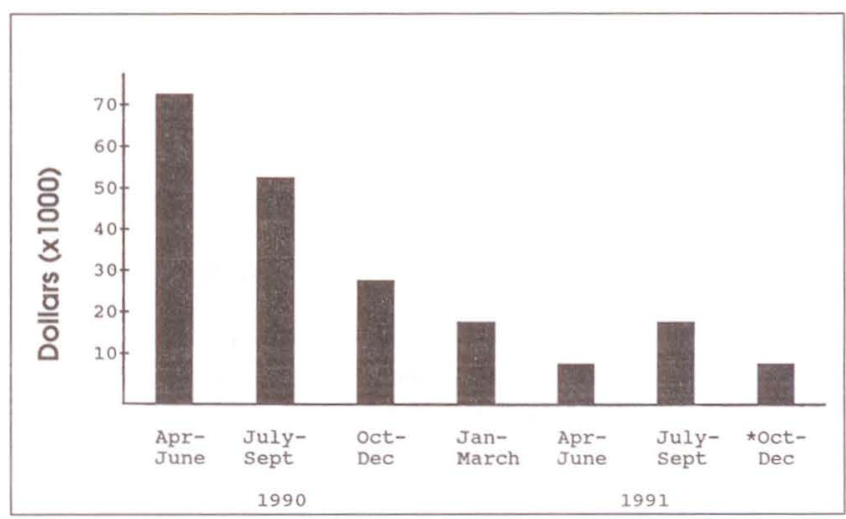

Figure 1) Cefoxitin use in dollars by quarterly intervals (199091). *Reflects price reduction from $\$ 11.50$ to $\$ 8.75 / \mathrm{g}$

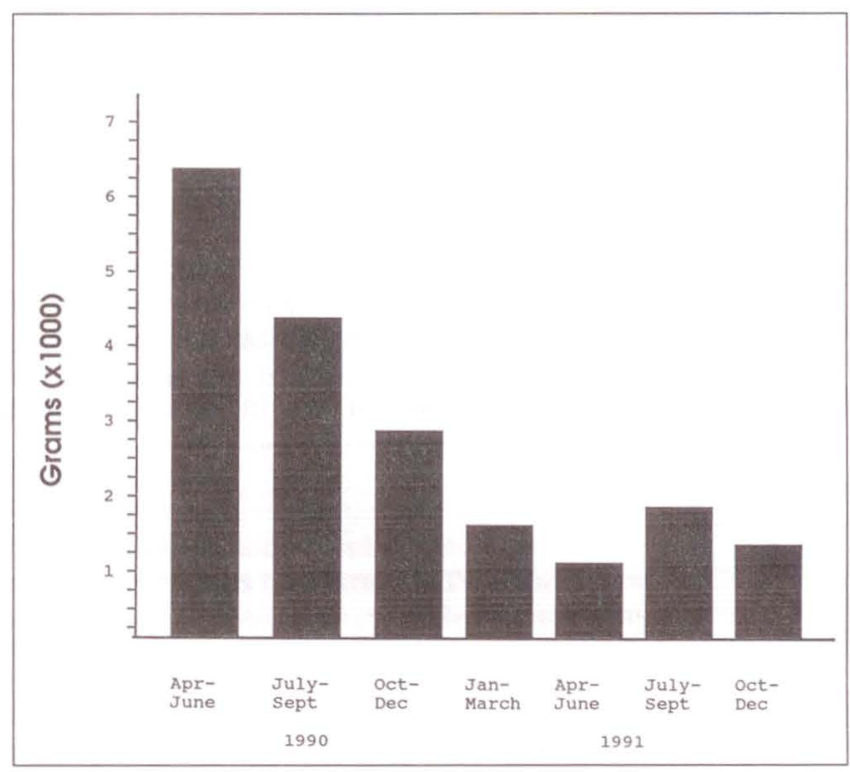

Figure 2) Cefoxitin use in grams by quarterly intervals (1990-91)

additional minor cost savings to be achieved by interchanging cefotetan or ceftizoxime for cefoxitin. If the suggested interchange of $1 \mathrm{~g}$ cefotetan or ceftizoxime for $2 \mathrm{~g}$ cefoxitin is adopted $(10,11)$, and the level of use of October to December 1991 persisted, the annual savings for substituting ceftizoxime would be approximately $\$ 17,108$, and for cefotetan, $\$ 6,580$.

At the time this study was initiated, the hospital was undergoing a severe budgetary crisis which ultimately resulted in bed closures and staff layoffs (19). The realization that drug cost savings would reduce the need to lay off staff and close beds likely contributed to medical staff's cooperation in the process. Major users of cefoxitin were asked to participate in the process and draw up their own guidelines for cefoxitin use in surgical prophylaxis. Such a self-directed educational strategy (in which learners are actively involved in the process) may be more effective than passive approaches to physician education, a strategy which has not always been successful (20). 


\section{REFERENCES}

1. Craig WA, Uman SJ, Shaw WR, et al. Hospital use of antimicrobial drugs: Survey at 19 hospitals and results of antimicrobial control program. Ann Intern Med 1978;89:793.

2. Hess DA, Mahoney CD, Johnson PN, et al. Integration of clinical and administrative strategies to reduce expenditures for antimicrobial agents. Am J Hosp Pharm 1990;47:585-91.

3. Kunin CM. The responsibility of the infectious disease community for the optimal use of antimicrobial agents. $J$ Infect Dis 1985;151:388-97.

4. Franson TR, Valenti WM. Strategies for antibiotic usage and utilization review: A comprehensive source book. Atlanta: American Health Consultants Inc, 1987.

5. Donowitz GR, Mandell GL. Cephalosporins. In: Mandell GL, Douglas RG, Bennett JE, eds. Principles and Practice of Infectious Diseases. New York: Churchill Livingstone, 1990:246.

6. Williams RR, Gross PA, Levine JF. Cost containment of the second-generation cephalosporins by prospective monitoring at a community teaching hospital. Arch Intern Med 1985;145:1978-81.

7. Ward A, Richards DM. Cefotetan: A review of its antibacterial activity, pharmacokinetic properties and therapeutic use. Drugs 1989;30:1-47.

8. Committee on Antimicrobial Agents, Canadian Infectious Disease Society. Ceftizoxime: A third-generation cephalosporin active against anaerobic bacteria. Can Med Assoc J 1990;142:1209-11.

9. Guastella C. Cost savings realized from interchanging ceftizoxime for cefoxitin. Am J Hosp Pharm 1988:45:2376-7.
10. Quintiliani R, Nightingale $\mathrm{CH}$. Antimicrobials and therapeutic decision making: An historical perspective. Pharmacotherapy 1991:11:6S-13S.

11. Wikler MA. Interchangeability of ceftizoxime and cefoxitin: A clinical perspective. Clinical Therapeutics 1990;12:74-9.

12. Kaiser AB. Antimicrobial prophylaxis in surgery. N Engl J Med 1986;315:1129-37.

13. Nichols RL. Prophylaxis for intraabdominal surgery. Rev Infect Dis 1984;6:S276

14. Anon. Antimicrobial prophylaxis in surgery. The Medical Letter on Drugs and Therapeutics 1987;29:91-4

15. McDonald, Karran SJ, Chir M. A comparison of intravenous cefoxitin and combination of gentamicin and metronidazole as prophylaxis in colo-rectal surgery. Dis Colon Rectum 1983;26:661-4

16. Aldridge KE, Wexler HM, Sanders CV, Finegold SM. Comparison of in vitro antibiograms of Bacteroides fragilis group isolates: Differences in resistance rates in two institutions because of differences in susceptibility testing methodology. Antimicrob Agents Chemother 1990;34:179-81.

17. Brook I. In vitro susceptibility vs. in vivo efficacy of various antimicrobial agents against the Bacteroides fragilis group. Rev Infect Dis 1990;13:1170-83.

18. McCloskey RV. Spontaneous reports of bleeding: Comparison of $\mathrm{N}$-methylthiotetrazole side chain (MTT) and non-MTT cephalosporins. J Infect Dis 1988;158:1405.

19. U of A Hospital lays off 100 staff. Edmonton Journal November 6, 1990.

20. Schroeder SA, Myers LP, McPhee SJ, et al. The failure of physician education as a cost containment strategy. JAMA 1984;252:225-30. 


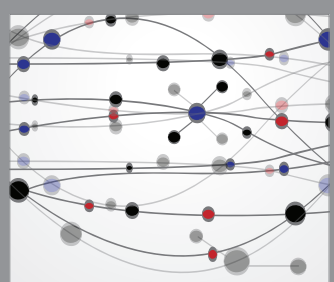

The Scientific World Journal
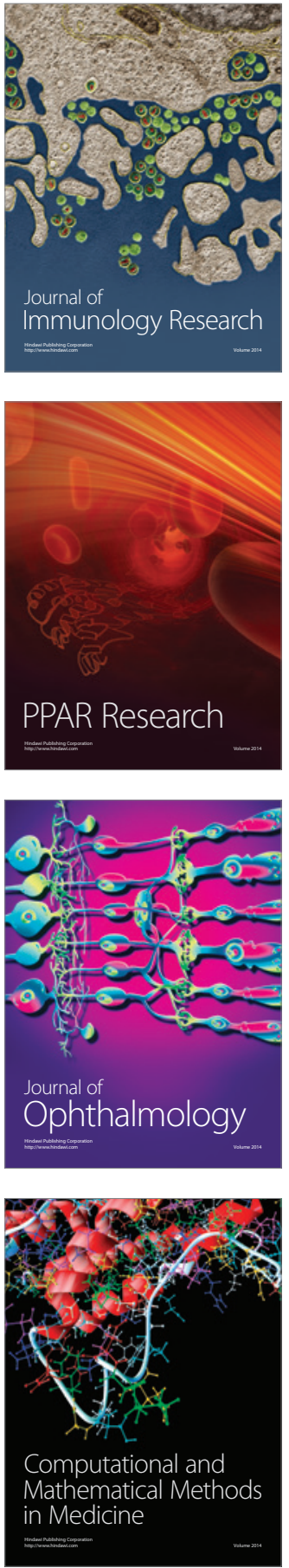

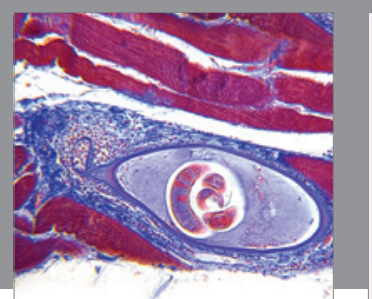

Gastroenterology Research and Practice

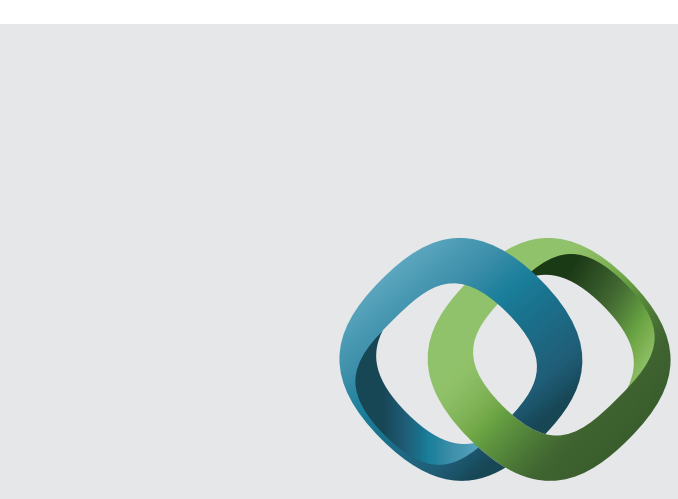

\section{Hindawi}

Submit your manuscripts at

http://www.hindawi.com
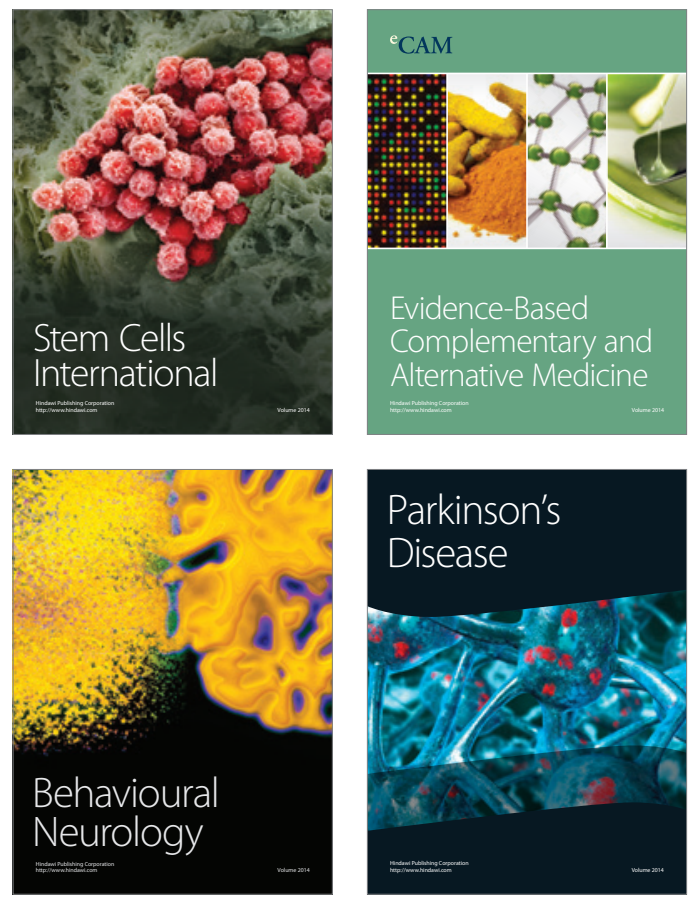
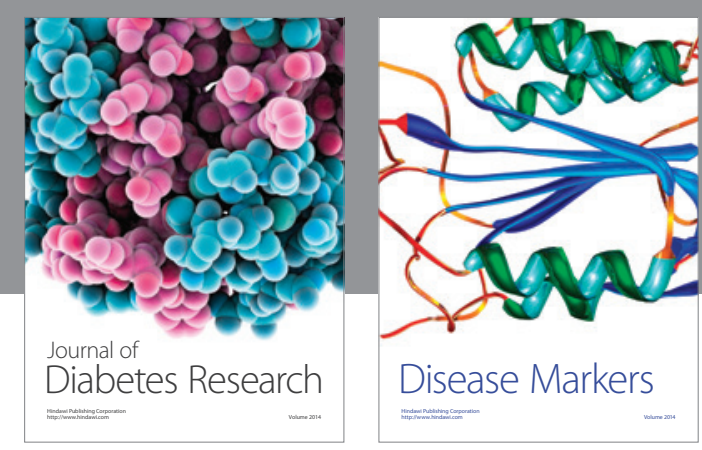

Disease Markers
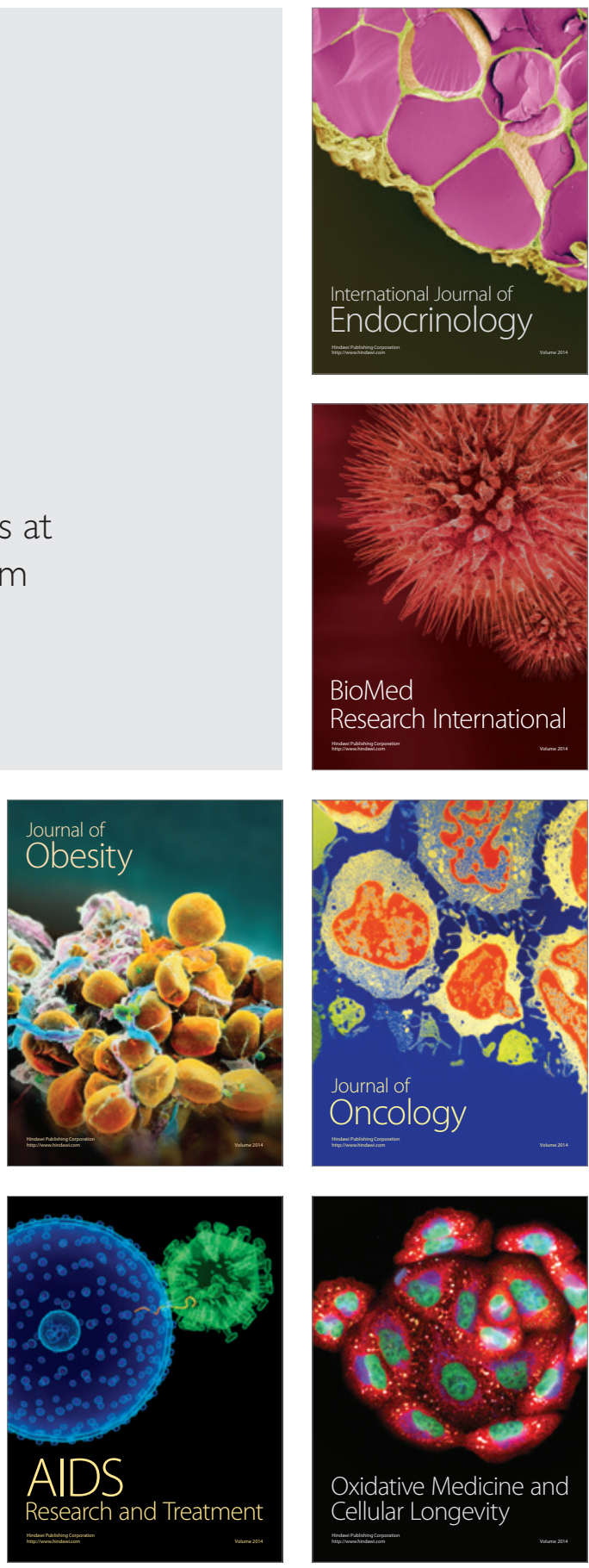